\title{
GLOBAL SATISFACTION WITHIN A UNIVERSITY SUBJECT (ORGANIZATIONAL BEHAVIOR AND CHANGE MANAGEMENT) AFTER USING PROJECT BASED LEARNING IN TIMES OF COVID-19
}

\author{
Vicente Guerola-Navarro, Raúl Oltra-Badenes, Hermenegildo Gil-Gomez \\ Departamento de Organización de Empresas. Universitat Politècnica de València (SPAIN)
}

\begin{abstract}
Project-based learning (PBL) is a learning methodology in which students take an active role and academic motivation is encouraged. The method consists of carrying out a project generally in a group, in which the theoretical concepts that give content to the teaching load of the subject are applied, and which has an eminently practical component.

In the subject "Organizational Behavior and Change Management" where PBL has been applied in previous courses, we have evaluated the impact of the use of PBL in the confinement situation derived from the COVID-19 pandemic in which classes have moved to taught telematically in the middle of the school calendar and in an unexpected and unplanned way. The results confirm that PBL is an effective and more efficient methodology if possible, in these circumstances.

Through direct and anonymous surveys to the students of the subject of this course, the impact of the use of PBL is evaluated both before and after the establishment of confinement and the move to online teaching.
\end{abstract}

Keywords: Organizational Behavior; Change Management; Project Based Learning; COVID-19; global satisfaction; subject evaluation.

\section{INTRODUCTION}

The objective of the present study is to evaluate the satisfaction of the students with the methodology of Project-Based Learning (PBL), applied in the teaching of the subject "Organizational Behavior and Management of Change", in an unknown environment such as that of the passing of face-to-face classes to telematics classes in the middle of the school calendar, and due to an unexpected and unforeseen situation such as that derived from the confinement imposed to fight the global health pandemic of COVID-19.

\section{1 "Organizational Behavior and Management of Change" University subject}

This study concerns "Organizational Behavior and Change Management", a University Subject, qualified as optative, with a load of 4.5 credits, which is taught in the 3rd year of the Degree in Informatics Engineering in the Universitat Politècnica de València (UPV). This study takes part concretely in the campus that UPV has in Alcoi, formerly Escuela Politècnica Superior de Alcoi (EPSA)

Organizational Behavior (OB) is the field of study of behavior and psychological processes in contexts related to work. Individual, group and organizational variables are part of the global scenario that may lead to improve performance [1]. What people do in an organization in order to facilitate the understanding of the complexity of the interpersonal relationships and people interactions, is the base to construct hypothesis about how that behavior affects the performance of the organization. It covers:

- individual variables: perception, learning and change of attitudes, motivation and satisfaction, design and stress at work;

- group variables: group work, group communication, leadership and conflict;

- organizational variables: politics, climate and culture and organizational change

The teaching guide of the subject includes the following competencies that should be gathered by the students at the end of the course: 
- Ability to understand and apply the principles of risk assessment and apply them correctly in the preparation and execution of action plans.

- Ability to integrate Information Technology and Communications solutions and business processes to meet the information needs of organizations, allowing them to achieve their objectives effectively and efficiently, thus giving them competitive advantages.

- Ability to understand and apply the principles and practices of organizations, so that they can act as a link between the technical and management communities of an organization and actively participate in the training of users.

- Locate relevant information from different sources and investigate technological developments in their field of work and related areas.

- Reason in an abstract, analytical and critical way, knowing how to elaborate and defend arguments in their area of study and professional field.

- Know how to apply their knowledge to their work or vocation in a professional way and possess the skills that are usually demonstrated through the elaboration and defense of arguments and the resolution of problems within their area of study.

With the profile of competencies described, and the general objective of the $\mathrm{OB}$ as a whole and as a definition, the approach of practical situations (and real, if possible) in which the student is in the process of evaluating a situational environment, and taking action decisions in the three settings described by the variables (individual, group, and social), seems one of the educational and teaching options with the highest expectations of success [2].

\subsection{Project Based Learning}

Boud and Feletti [3] define PBL as "a way of constructing and teaching courses using problems as the stimulus and focus for student activity". The core principle of Problem-based learning (PBL) is the active role of students in the construction of knowledge [4]. Everything translates into the line of argument that the more the student gets involved in their own learning, the greater the effectiveness of the training activity [5]. Ponsa et al. [6] states that PBL methodology drives to success the preference of the students for practical sessions, with the result of clear increase of the student's participation and their motivation. Practical applications of PBL have been recently developed in Universitat Politécnica de Valencia with high satisfaction reported by students and participants [7].

The present paper aims to evaluate this type of PBL learning applied to this subject and under very specific conjunctural conditions (COVID-19). Having stated PBL as the initial teaching methodology plan for this course, and having unexpectedly jumped into confinement conditions due to COVID-19 pandemic at the middle of academic calendar, the objective will be to evaluate the impact of this PBL in the transition to new teaching conditions.

\subsection{COVID-19 pandemic and confinement effects}

Coronaviruses are a large family of viruses which may cause illness in animals or humans. In humans, several coronaviruses are known to cause respiratory infections ranging from the common cold to more severe diseases such as Middle East Respiratory Syndrome (MERS) and Severe Acute Respiratory Syndrome (SARS). The most recently discovered coronavirus causes coronavirus disease COVID-19 [8]. COVID-19 is now a pandemic affecting many countries globally. In order to avoid contagion between people, one of the recommendations is when possible maintain at least a 1 meter distance between yourself and others. Due to these councils, the health and executive authorities of the countries with a high degree of infection, have determined as a precautionary measure the confinement of the population. In the academic field, this measure has led universities to close classrooms and transform teaching the rest of the current course into telematics. This unexpected and unforeseen situation in academic structures and procedures has had an impact on the way in which teachers have continued to teach classes, and in the same way on students.

\section{METHODOLOGY}

For learning based on the PBL system, the practical application of theoretical concepts must follow a coherent and consistent line of argument in each of its stages, interrelated with previous and subsequent training actions, and have an eminently practical character, which involve students and 
motivate them in their active participation. Therefore, a structure of practices and exams with an applied and consistent character has been designed. One of the most powerful tools to check the efficiency of the method will be the students' own evaluation through a feedback and improvement questionnaire.

\subsection{PBL plan for the present course and adaptation to on-line teaching during COVID-19 confinement}

The subject was initially proposed, according to the Teaching Guide, as a way to acquire the basic skills that guarantee effective learning. For this, the following scheme is proposed at the beginning of the course:

- 4 practices

- NASA practice

- Bunker practice and atomic disaster

- Practice of a Kotter model on change management

- Change management practice applied

- 2 exams

- Exam $1^{\circ}$ with 15 test questions and 4 short answer questions

- Exam $2^{\circ}$ with 15 test questions and 4 short answer questions

\subsubsection{Initial Planned Practices}

The planned plan for the internships follows the PBL line through a common project for the development of competences.

\section{+ Practice 1-NASA practice}

NASA's game is a group dynamic organized around a spacecraft crash landing on an unexpected part of the moon; the crew must organize and decide (in a group) what they will take with them in search of the permanent base that will be their salvation. At the beginning of the course, and with this practice, students face a first situation, prepared and aimed at highlighting the importance of expecting the unexpected, working as a team, and solving the differences and inefficiencies of teamwork between them. The expected outcome is to value the starting point of the class group as a compact system and from the point of view of collaboration and management of interpersonal relations in the group environment. The main objectives are then two key competences: individual and group skills during decision making sessions.

\section{+ Practice 2 - Bunker practice and atomic disaster}

The next level of practical learning is the one that involves the social dimension of decision making. The exercise consists in assuming that, due to an atomic disaster, only 12 people remain (with different and marked stereotypes), and among them they have to decide which 5 will enter the bunker and be saved, being the beginning of a future existence on Earth. In this practice, students are put in a position to make decisions under stressful conditions, with a view to the survival of the spice. The learning project is therefore progressing in a practical way towards covering the third and maximum dimension of Organizational Behavior, which is the social one. The learning pursued in this practice is to evaluate the influence of stereotypes in decision-making involving interpersonal relationships. It is therefore the logical evolution and applied to practice 1.

\section{+ Practice 3-Kotter model}

After evaluating and highlighting the management skills of the individual, group, and social dimensions of the students, the next exercise of the Learning Project will be to become aware of the practical difficulties of decision making when the presence of important changes is anticipated. , counting on the psychological effect of "resistance to change". Following the Kotter model [9], students are placed in a position to develop strengths in the management of interpersonal relationships for the "adoption of change". 


\section{+ Practice 4-Change Management}

All the skills developed in the previous practices are applicable in the final practice, in which a practical example of eminent actuality will give students the option to put to work their strengths for planning, deployment, and management of personal expectations (individual, group and social) for the best result in the adoption of a certain change of social impact. With this group dynamic the line of the Common Project of practical training of the course will be finished.

\subsubsection{Adaptation of the planned Practices}

After having carried out the first two practices in person in the classroom, confinement occurs due to the COVID-19 pendemic, and the need to carry out Practices 3 and 4 remotely is raised, and following the principles of PBL, the way of motivating students to become actively involved in their development and learning. For this, the approach is not modified, but the themes are changed, deriving the content to two situations of eminent relevance:

- Practice 3 establishes how a group work in which students must propose an adaptation plan to one of the following situations:

- launch an online learning model so that the students of the Polytechnic University of Valencia adopt change and reinforce their commitment to actively and efficiently participate in their own learning (case of real application actually).

- launch a plan for the adoption of a productive change in a company that manufactures sheets, and that in the face of sanitary needs, decides to manufacture sanitary material and do so with the maximum guarantees of non-contagion among its workers

- Practice 4 becomes a work of investigation and debate on the changes that society is going to have to face as a consequence of new social and health habits, preventive and necessary to combat the spread of COVID-19. Again focused on reinforcing the most efficient way to facilitate change. As in practice 3 , again a case of eminent current events to motivate students.

\subsubsection{Exams}

The planning of the exams changes completely with the shift of teaching from the face-to-face format to the online format. The option of evaluating students through test-type or short-answer questions is abandoned and is committed to reinforcing the line of work of the educational project undertaken at the beginning of the course according to PBL. The two exams become two practical cases, the first as a continuation of practice 2 and the prelude to practice 3 , the second in the same way interconnected with practices 3 and 4 .

Exam 1 proposes to the students that, individually, and as a previous step to practice 3 (where they will do it in groups), establish their recommendations and management models of personal expectations for the sudden adoption of the step to online teaching.

Similarly, Exam 2 proposes that students, once again individually, and as a previous step to practice 4 (where they will do so in a group), establish their parameters on organizational behavior to be taken into account in predicting what will be impersonal relationships (group and social) after the COVID-19 pandemic.

\subsection{Follow-up about the plan (survey to students)}

A questionnaire has been designed in order to receive feedback from students about the global satisfaction with the PBL plan executed during the actual course, end even more with the change into online teaching at the middle of the course.

The questionnaire that was designed and presented to the students was composed of 10 questions shown below and adapted from Oltra-Badenes [10]:

1 I think this course will be useful in my professional future.

2 The content of the subject seems interesting to me.

3 I think what I will learn in this subject class is important.

4 I think understanding this subject will cost me more than the rest.

5 Do you think the use of PBL has been the most appropriate for this course? 
6 What do you think of Organizational Behavior and Change Management from the point of view of a GII / GADE?

7 How has your perception of Organizational Behavior and Change Management changed since the beginning of the course?

8 Why? Anything to be with COVID-19?

9 Do you think that any of the previous questions would have a different answer if the current situation (teaching conditions) derived by COVID-19 had not occurred?

10 Which of the questions would have a different answer? How would the response have varied?

The answers to the 5 first questions in this survey correspond to a Likert scale [11], from 1 to 5 , in which the meaning of each answer is:

1 Totally agree

2 Agree

3 Medium term (neither agreement nor disagreement)

4 Disagree

5 Strongly disagree

The answers to the answers 6 to 10 are supposed to have free short-answer.

Of the 14 students that the subject has, one of them with exemption from class attendance (and therefore not having participated in the sessions), 12 responded to this questionnaire, representing $85 \%$ of the total and $92 \%$ of the attendees. Therefore, the sample is considered sufficiently representative of the population.

\section{RESULTS}

The results collected in the surveys for the $\mathbf{5}$ first questions on Likert scale are those shown below in Table 1.

Table 1. Results collected in the surveys. Source: self-made

\begin{tabular}{|l|c|c|c|c|c|}
\hline & $\begin{array}{c}1 \\
\text { Totally } \\
\text { agree }\end{array}$ & $\begin{array}{c}2 \\
\text { Agree }\end{array}$ & $\begin{array}{c}3 \\
\text { Medium } \\
\text { term }\end{array}$ & $\begin{array}{c}4 \\
\text { Disagree }\end{array}$ & $\begin{array}{c}5 \\
\text { Strongly } \\
\text { disagree }\end{array}$ \\
\hline 1. I think this course will be useful in my professional future & 5 & 4 & 3 & & \\
\hline 2. The content of the subject seems interesting to me & 4 & 5 & 3 & & \\
\hline 3. I think what I will learn in this subject class is important & 4 & 6 & 2 & & \\
\hline $\begin{array}{l}\text { 4. I think understanding this subject will cost me more than } \\
\text { the rest }\end{array}$ & & & & & 12 \\
\hline $\begin{array}{l}\text { 5. Do you think the use of PBL has been the most } \\
\text { appropriate for this course? }\end{array}$ & 9 & 3 & & & \\
\hline
\end{tabular}

Observing the values obtained in Table 1:

- The first observation made in this table is that $75 \%$ of the students consider that the content and development of this subject will be useful or very useful in their professional future, with only $25 \%$ indifferent and none at odds with the usefulness of The subject.

- On the other hand, again $75 \%$ of students consider the content of the subject as interesting or very interesting, and only $25 \%$ are indifferent to this statement. Again, no one thinks it is not interesting.

- Besides, the $83 \%$ of the students think that what has been learned in class is important, and only $17 \%$ are indifferent. No student thinks that learning in this area is not important.

- Regarding its difficulty, $100 \%$ of the students think that understanding this subject should not cost more than it can cost for the rest. 
- To finish, $100 \%$ think that the PBL method has been the most suitable for this subject and this course.

Regarding the last 5 questions (free short answer), these are the comments obtained from the questionnaires (only 6 students have filled them):

6 What do you think of Organizational Behavior and Change Management from the point of view of a GII / GADE?

a) I think it is an important subject that is not usually dealt with, they tend to focus on concepts, and on how to do things, but not on the human side.

b) The truth is that I think it is necessary to provide students with this vision of how to function in a company, with the aim of working in a pleasant and comfortable environment. Being aware at all times of no company works the same

c) I find it a most interesting subject since it gives you work situations to face with different points of view, different personalities that you can meet, and know how to face different work challenges

d) That it is a very necessary knowledge in terms of its treatment and learning to cope in situations not only at work (although the subject is focused on that area) but also on a dayto-day basis in which we interact with other people and facilitate understanding and face any type of change or situation

e) I would like to work with empathetic, hard-working, positive and pleasant people to debate with, and I would like my colleagues to think that about me.

f) It is good to keep in mind the concepts that are given in the subject, regardless of the training that is

7 How has your perception of Organizational Behavior and Change Management changed since the beginning of the course?

a) It has changed favorably

b) Since the beginning of the course I have shown interest in the subject since it is a group not too small for the classes to become boring. But since the first day the work environment in class has always been very good and interesting

c) You realize the importance of "work psychology" if it can be called that

d) Although all the concepts given throughout the course have been known to me, the way of treating and analyzing them, as well as applying them to different areas of our daily social iteration, has helped me a lot to approach any behavior in a different way, and on all applying a much-needed understanding and empathy in any type of situation

e) Before I thought that it was something innate in people, that a person was empathetic or positive from birth, that is, because of their education. Now I think it is something that can be worked on and promoted for their own benefit, to grow in the workplace and establish better working relationships.

f) I think not much has changed

8 Why? Anything to be with COVID-19?

a) After finishing the course I have realized that a company is a team, with each component different from the others and this implies a different behavior for each one, but we all have the same objective and we must work and / or manage changes to achieve it. Even more related to how to deal with people during COVID-19.

b) Above all, because of the internships, because they are obliged to work in a group and have to be participative, and what I like the most, to let imagination and expression fly

c) I think you realize how to face working life in a group, that is, when you work as a team you cannot obviously think individually, and with this subject you realize different ways of facing work, whether you are available to someone as if you have a group of people in your charge as a group leader

d) Because many times we act without realizing what is happening or how it affects our surroundings, after various exercises and reflections in class, it helps to realize the 
importance of knowing that we are not alone, that we are surrounded by other people who think, feel and also they act, and as we have our own reasons and truth, the rest of the world also, and sometimes it is necessary to be aware of the needs and feelings that others have and what pushes them to develop one behavior or another

e) By studying optimal behaviors, you reflect on your own in the workplace (either at the educational level or at the job level). In my case, although I consider myself a person with emotional intelligence, I think that it is something that can be enhanced and worked to get the most out of this advantage, and that can have very good results at work level. Before I just thought it was something that depended on your attitude, now I think it is an advantage that can be worked on and that can be very beneficial both in the future and today.

f) For me it is something of common sense and very evident, in my case I do not need to take a subject to know most of the concepts seen

9 Do you think that any of the previous questions would have a different answer if the current situation (teaching conditions) derived by COVID-19 had not occurred?

a) I think that, if the current situation had not happened, we could have enjoyed this subject even more, we could have seen and felt with our own skins the different aspects of the subject and with it, have learned more and more efficiently.

b) I honestly believe that the teacher-student connection has been very good and we have known how to enjoy the few days of class. If this situation has avoided being able to continue with the class dynamics and the theory classes have become more boring, because it is not the same environment that is created in the classroom with your classmates than only at home. So the answer would have been the same; the only thing that would have changed is the introduction of this

c) No

d) The truth is that no, although it has been a shame, because the physical interaction with the virtual one is obviously not comparable, the knowledge transmitted after all has been the same, and the university has taken care to provide us with the virtual means to do so.

e) The subject seemed interesting to me since it was raised. The situation derived from COVID has only been a nuisance because it has not allowed us to develop it as expected. One of the most interesting things about the subject was group practice, which we could not do in the way that was established and that seemed so interesting to me.

f) No, for sure.

10 Which of the questions would have a different answer? How would the response have varied?

a) No (x6).

\section{CONCLUSIONS}

Both the quantified responses and the free exposure responses show a high degree of satisfaction with the content and development of the subject, with no answer in disagreement and very few showing indifference. More than $75 \%$ of the students have shown a high degree of satisfaction with the usefulness of the subject, with their interest and with their importance in their development of professional skills. Also all the students opt for evaluating PBL as the best methodology for the development of this subject.

Among the free-range answers obtained, practically all of them show a high degree of satisfaction with the content and development of the subject. Most of them show an increase in their personal assessment of the theme of Organizational Behavior and Change Management as relevant and key to good group and social functioning. They also show a high awareness that the impact of the skills developed in the subject can lead to success in the operation of interpersonal relationships in companies. Only one of the students expressed his disagreement that this subject should be included as one of the subjects of his curriculum.

Regarding the impact that confinement and the move to online teaching, derived all from the COVID19 pandemic, all the responses show that precisely the use of PBL as a teaching methodology has influenced that all the responses have not changed, and that therefore this applied methodology has guaranteed continuity in learning despite the drastic change in circumstances. 


\section{REFERENCES}

[1] Robbins, S. P., Judge, T. A., \& Pineda Ayala, T. A. Comportamiento organizacional. México: Pearson Educación, 2013

[2] Guerola-Navarro, V.; Oltra-Badenes, R.F.; Gil-Gómez, H.; \& Herrero-Casanova, M. (2019). Experience of external collaboration in Organizational Behavior and Change Management subject in practical lesson. In 12th International Conference of Education, Research and Innovation (ICERI 2019). (pp. 289 - 294). Sevilla, España: IATED.

[3] Boud, D., \& Feletti, G. (2013). The challenge of problem-based learning. Routledge.

[4] Araújo, U. F., Fruchter, R., Garbin, M. C., Pascoalino, L. N., \& Arantes, V. (2014). The reorganization of time, space, and relationships in school with the use of active learning methodologies and collaborative tools. ETD: Educaçao Temática Digital, 16(1), 84-99

[5] Gudwin, R. R. (2015). Aprendizagem ativa. Retrieved from: http://faculty.dca.fee.unicamp.br/gudwin/activelearning

[6] Ponsa, P., Amante, B., Román, J. A., Oliver, S., Díaz, M., \& Vives-Gràcia, J. (2009). Higher education challenges: introduction of active methodologies in engineering curricula. International Journal of Engineering Education, 25(4), 799-813

[7] García Bernabeu, A.; Guerola-Navarro, V.; Bravo Selles, M.; Oltra Crespo, S.; Agud Albesa, L.; \& Perez-Bernabeu, E. (2020) Problem-based learning for cross-curricular competences assessment of business administration degree students: the Activat innovative education project. In 14th annual International Technology, Education and Development Conference (INTED 2020). (pp. 923-929). Valencia, España; IATED

[8] World Health Organization (WHO) (2020). WHO Coronavirus Disease (COVID-19) Dashboard. Retrieved from: https://www.who.int/emergencies/diseases/novel-coronavirus-2019/question-andanswers-hub/q-a-detail/q-a-coronaviruses.

[9] Kotter, J., \& Bourner, T. (1998). Leading change. Technovation, 18(4), 294-294.

[10] Oltra-Badenes, R. (2018). Protocol: What is the perception that students have of a subject? Application to the subject Integrated Information Systems of the Degree in Industrial Organization Engineering. Working Papers on Operations Management, 9(2), 112-126.

[11] LIKERT, Rensis. A technique for the measurement of attitudes. Archives of psychology, 1932. 